\title{
CONDIÇÕES HIGIÊNICO-SANITÁRIAS DE MANIPULADORES DE ALIMENTOS DE UMA UNIDADE DE ALIMENTAÇÃO E NUTRIÇÃO NA CIDADE DE UBERLÂNDIA, MINAS GERAIS
}

Beatriz Silva de Sousa ${ }^{1}$ Lizandra Ferreira de Almeida e Borges $^{2}$ Renata Aparecida Mendes $^{3}$

${ }^{1}$ Residente do Programa de Residência Multiprofissional e em Área Profissional da Saúde da Faculdade de Medicina da Universidade Federal de Uberlândia Uberlândia-MG

${ }^{2}$ Docente do Instituto de Ciências Biomédicas da Universidade Federal de Uberlândia - Uberlândia-MG

${ }^{3}$ Docente da Faculdade de Medicina da Universidade Federal de Uberlândia Uberlândia-MG (e-mail: renatanutri@ufu.br)

Recebido em: 03/10/2016 - Aprovado em: 21/11/2016 - Publicado em: 05/12/2016 DOI: 10.18677/EnciBio_2016B_132

\begin{abstract}
RESUMO
A contaminação das mãos dos manipuladores está dentre os fatores que contribuem para o surgimento de doenças transmitidas por alimentos. O objetivo desse estudo foi avaliar as condições higiênico-sanitárias de manipuladores de uma unidade de alimentação e nutrição. A população de estudo foi composta por 30 manipuladores, avaliados por um checklist para levantamento observacional de higiene e por um questionário para obtenção de informações socioeconômicas e de hábitos de higiene. Foi realizada coleta microbiológica das mãos pelo método do saco estéril de polietileno, para avaliação da presença de coliformes totais e termotolerantes e contagem total de micro-organismos mesófilos aeróbios (UFC/mão) e Staphylococcus spp. Dentre os manipuladores avaliados, $56,7 \%$ eram do sexo feminino, com faixa etária predominante de 25 a 45 anos $(66,7 \%)$, e nível de escolaridade médio completo (36,7\%). A maioria dos itens avaliados no checklist teve grande porcentagem de adequação (85 a 95\%), exceto o item "comportamento dos manipuladores" que obteve $14 \%$. A maioria das amostras $(93,3 \%)$ apresentou contagens de micro-organismos mesófilos aeróbios variando entre 4,5 x $10^{3}$ a 7,7 x $10^{5} \mathrm{UFC} /$ mão. Não foram detectados coliformes termotolerantes e Staphylococcus aureus em nenhuma das amostras e em 3,33\% foi constatada a presença de coliformes totais. Foi constatado que os manipuladores avaliados faziam a higienização das mãos satisfatoriamente, pelo fato de não encontrar contaminação por micro-organismos epidemiologicamente importantes, recuperando a microbiota normal da pele. No entanto, observou-se que fatores relacionados ao comportamento dos manipuladores podem propiciar a contaminação dos alimentos durante a preparação.
\end{abstract}

PALAVRAS-CHAVE: bactéria, mãos, serviço de alimentação. 


\title{
HYGIENIC AND SANITARY CONDITIONS OF FOOD HANDLERS AT A FOOD SERVICE IN UBERLANDIA, MG, BRAZIL
}

\begin{abstract}
The contamination of the hands of manipulators are among the factors contributing to the appearance of foodborne diseases. The aim of this study was to evaluate the hygienic and sanitary conditions of food handlers at a food service in Uberlandia, MG, Brazil. The study population consisted of 30 food handlers, evaluated by a checklist for observational survey of hygiene, socio-economic and hygienic-sanitary information. Microbiological collection of hands by the method of sterile polyethylene bag also realized for evaluation of total and fecal coliforms and Staphylococcus spp. and aerobic mesophilic count. Among the evaluated handlers, 56.7\% were female, with predominant age group 25-45 years (66.7\%), and completed high school level $(36.7 \%)$. Were observed higher adequacy rates (85-95\%) in most health rules related to handlers. There was no presence of fecal coliform in any sample and presence of total coliforms in only $3.33 \%$ of the samples. The majority $(93.3 \%)$ had counts of aerobic mesophilic ranging from $7.7 \times 10^{5}$ to $4.5 \times 10^{3} \mathrm{CFU} /$ hand. All samples were negative for Staphylococcus aureus species. The evaluated handlers have hand hygiene satisfactorily, because we not found contamination of epidemiologically important microorganisms, recovering the normal skin flora. However, observed that some behaviors that can lead to the contamination of food during preparation.
\end{abstract}

KEYWORDS: bacteria, hands, food services.

\section{INTRODUÇÃO}

A qualidade sanitária das preparações alimentares servidas em unidades de alimentação e nutrição (UANs) é essencial, considerando que o público atendido é amplo e que os inúmeros locais que oferecem esses serviços estão frequentemente envolvidos em surtos de doenças transmitidas por alimentos (CARDOSO et al., 2005).

No Brasil, de 2000 a 2015, foram notificados 10.666 surtos de doenças transmitidas por alimentos (DTAs), sendo que das 2.107.229 pessoas que foram expostas, 209.240 ficaram doentes e 155 foram a óbito. Nos surtos, os agentes etiológicos identificados foram bactérias, vírus e parasitas. As ocorrências ocorreram, na maior parte, em residências e, em segundo lugar, em restaurantes, padarias e similares (BRASIL, 2015). Embora os dados brasileiros estejam subestimados devido à baixa notificação dos surtos, estes indicam que ainda há necessidade de se controlar a contaminação microbiana durante o preparo dos alimentos. Nos Estados Unidos, onde a notificação dos surtos é mais efetiva, a cada ano, 76 milhões de pessoas ficam doentes, 300 mil são hospitalizadas e 5.000 vão a óbito em decorrência de doenças transmitidas por alimentos (CDC, 2004). Neste país, somente em 2010, foram notificados 48 milhões de casos de doenças transmitidas por alimentos e 3.000 mortes (SCHARFF, 2012).

Os alimentos podem se contaminar devido a falhas no processamento dos mesmos, como: refrigeração inadequada, processamento térmico insuficiente, preparo do alimento com amplo intervalo de tempo entre o preparo e consumo, contaminação cruzada, conservação imprópria, ingredientes contaminados, incorreta higienização de utensílios, mãos dos manipuladores de alimentos, entre outros (ABREU et al., 2011). 
Muitos patógenos são transmitidos aos alimentos pelas mãos dos manipuladores. Isso ocorre quando não há a correta higiene das mãos após o uso das instalações sanitárias, manuseio de alimentos crus, transporte de lixo ou uso de produtos de limpeza. Dentre os patógenos geralmente transmitidos do manipulador para o alimento estão Bacillus cereus; Campylobacter jejuni; Clostridium perfringens; Escherichia coli enteropatogênica; Salmonella spp; Shigella spp; Staphylococcus aureus; Streptococcus pyogenes; Vibrio cholerae e Yersinia enterocolitica (CDC, 2014).

Algumas medidas podem ser tomadas para que os manipuladores não se tornem responsáveis pela contaminação dos alimentos como a adoção de treinamentos frequentes e capacitação quanto à higienização correta das mãos, além da conscientização por parte deles sobre como são importantes na preparação de um alimento seguro (CONCEIÇÃO \& NASCIMENTO, 2014).

Visto que as doenças transmitidas por alimentos consistem em um problema de saúde pública, e que a higiene dos manipuladores de alimentos é um dos fatores que mais contribuem para o controle das mesmas, este estudo teve como objetivo avaliar as condições higiênico-sanitárias de manipuladores de uma unidade de alimentação e nutrição da cidade de Uberlândia, Minas Gerais.

\section{MATERIAL E MÉTODOS}

Trata-se de um estudo de corte transversal realizado com uma amostra de conveniência, composta por 30 manipuladores de uma Unidade de Alimentação e Nutrição da cidade de Uberlândia/MG. Os manipuladores foram escolhidos aleatoriamente e participaram do estudo após assinarem o Termo de Consentimento Livre e Esclarecido (TCLE), sendo este projeto aprovado pelo Comitê de Ética em Pesquisa com Seres Humanos da Universidade Federal de Uberlândia sob o número 633.055/2014.

Foram avaliados dados pessoais e questões de higiene dos manipuladores por meio de questões aplicadas individualmente a cada participante da pesquisa e questões higiênico-sanitárias do ambiente de trabalho por um checklist elaborado pelos pesquisadores, baseado nas recomendações da RDC 216 de 2004, da Agência Nacional de Vigilância Sanitária (BRASIL, 2004). O checklist foi aplicado em cinco ocasiões distintas, com período de observação de 40 minutos em cada visita ao estabelecimento.

Para a coleta das amostras microbiológicas, a mão dominante do manipulador de alimentos foi inserida dentro de um saco de polietileno esterilizado, contendo 75 $\mathrm{mL}$ de Caldo Tripticase Soja, enriquecido com $0,1 \%$ de Tween 80 . A mão do manipulador foi massageada dentro do saco por um minuto, abrangendo o pulso, os dedos, ao redor das unhas e a palma da mão. Após a coleta, o material, lacrado e etiquetado, foi transportado ao Laboratório de Microbiologia da Universidade Federal de Uberlândia em caixa isotérmica adicionado de gelo em gel. A solução foi agitada de baixo para cima 25 vezes durante sete segundos, de acordo com a norma da Associação Americana de Saúde Pública (LARSON et al., 1980). Posteriormente um $\mathrm{mL}$ das amostras foram diluídas em tubos com nove $\mathrm{mL}$ de solução salina $0,85 \%$ para obtenção das diluições decimais seriadas.

Para a contagem total de micro-organismos mesófilos aeróbios, foram inoculados um $\mathrm{mL}$ das diluições homogeneizadas pela técnica de superfície, em placas contendo Agar para Contagem (PCA), com auxílio de uma alça de Drigalski. 
As placas foram incubadas a $37^{\circ} \mathrm{C}$ por 24 horas e então quantificado a quantidade número de unidades formadoras de colônias por mililitro (UFC/mL).

Considerando a utilização de $75 \mathrm{~mL}$ de caldo para recuperar a amostra, utilizou-se a fórmula UFC/mão $=$ UFC $/ \mathrm{mL} \times 75 \mathrm{~mL}$ para determinar a contaminação das mãos. Os resultados foram expressos em Unidades Formadoras de Colônia/mão (UFC/mão).

Para a detecção de coliformes totais e termotolerantes foram inoculadas alíquotas de um $\mathrm{mL}$ das diluições decimais preparadas em tubos contendo nove $\mathrm{mL}$ de Caldo Verde Brilhante e em tubos com o mesmo volume de Caldo Escherichia coli (EC), todos com um tudo de Durhan invertido. As amostras foram incubadas a $37^{\circ} \mathrm{C}$ por 48 horas e a $45^{\circ} \mathrm{C}$ por 24 horas, respectivamente. Os tubos com turvação e produção de gás no interior do tubo de Durhan foram interpretados como positivos e os resultados expressos como presença ou ausência desses micro-organismos.

A análise de Staphylococcus spp. nas amostras de mãos foi realizada pela tomada de uma alíquota de um $\mathrm{mL}$ da diluição 1:10 cultivada em Agar Manitol Salgado, com incubação a $37^{\circ} \mathrm{C}$, por 24 a 48 horas. As colônias características foram analisadas pela técnica da coloração de Gram, seguidas de identificação pelo teste da catalase, pela prova da coagulase ligada e confirmação da espécie pelo teste da DNAse, em Agar DNAse incubado a $37^{\circ} \mathrm{C}$ por 24 horas, revelado com solução de $\mathrm{HCl} 1 \mathrm{~N}$ (KONEMAN et al., 2001).

\section{RESULTADOS E DISCUSSÃO}

Dentre os manipuladores avaliados, $56,7 \%$ eram do sexo feminino, com faixa etária predominante de 25 a 45 anos (66,7\%), e nível de escolaridade médio completo $(36,7 \%)$. A maioria dos manipuladores trabalha na área há mais de dois anos $(86,7 \%)$, recebe de um a dois salários mínimos, e está satisfeito com a profissão (93,3\%), conforme Tabela 1.

TABELA 1. Avaliação socioeconômica de manipuladores de uma Unidade de Alimentação e Nutrição, na cidade de Uberlândia-MG.

\begin{tabular}{lc}
\hline Variáveis & $\mathrm{N}=30(\%)$ \\
\hline Sexo Feminino & $17(56,7)$ \\
Masculino & $13(43,3)$ \\
Faixa etária & $5(16,7)$ \\
18 a 25 anos & $20(66,7)$ \\
25 a 45 anos & $05(16,7)$ \\
Mais de 45 anos & $10(33,3)$ \\
Escolaridade & $4(13,3)$ \\
Fundamental completo & $11(36,7)$ \\
Fundamental incompleto & $4(13,3)$ \\
Médio completo & $1(3,3)$ \\
Médio incompleto & $12(40)$ \\
Superior incompleto & $18(60)$ \\
Renda mensal & \\
Até 1 salário mínimo & $28(93,3)$ \\
De 1 a 2 salários mínimos & $2(6,7)$ \\
Satisfação com a profissão & \\
Sim & \\
Não &
\end{tabular}


Na Tabela 2 está apresentada a avaliação sobre hábitos higiênicos dos manipuladores de alimentos. Dos manipuladores estudados, $90 \%$ foram submetidos a cursos sobre higiene e segurança alimentar e estes são frequentemente oferecidos pela UAN, diferentemente dos resultados encontrados por MESSIAS et al. (2013), que observaram que a maioria dos restaurantes analisados não possuía programas de capacitação adequados e contínuos para os manipuladores de alimentos. Porém, cabe ressaltar que mesmo sendo submetidos a cursos, os manipuladores podem agir de forma incorreta durante o trabalho, o que foi comprovado por LUZ \& FORTUNA (2015), que encontraram contaminação microbiológica nas mãos e alguns hábitos inadequados em manipuladores já submetidos a treinamentos. No presente estudo, um manipulador afirmou não seguir o que aprendeu nos cursos e outro afirmou nem sempre seguir as recomendações, o que reforça a importância do frequente monitoramento das atividades de manipulação de alimentos. Em um estudo realizado por TAKAHASHI et al. (2013) foi verificado nas análises microbiológicas redução da carga orgânica de aproximadamente 10 vezes nas mãos dos manipuladores de um dos restaurantes avaliados após a participação deles em um treinamento a respeito das boas práticas de manipulação, demonstrando a importância desses treinamentos.

TABELA 2. Condições e hábitos dos manipuladores de uma Unidade de Alimentação e Nutrição, na cidade de Uberlândia-MG.

\begin{tabular}{lc}
\hline \hline Variáveis & $\mathrm{N}=30(\%)$ \\
\hline \hline Já fez algum curso sobre higiene ou segurança de & \\
alimentos? & $25(83,3)$ \\
Sim, e sigo o que aprendi no curso & $1(3,3)$ \\
Sim, e nem sempre sigo o que aprendi no curso & $1(3,3)$ \\
Sim, e não sigo o que aprendi no curso & $3(10)$ \\
Não, mas tenho vontade de fazer & \\
Quantas vezes você lava as mãos durante o serviço? & $2(6,7)$ \\
De 3 a 5 vezes & $28(93,3)$ \\
Mais de 5 vezes & $30(100)$ \\
Você lava as mãos após usar o banheiro? & - \\
Sim & $30(100)$ \\
Não & - \\
Você lava as mãos quando chega ao serviço? & $22(73,3)$ \\
Sim & $1(3,3)$ \\
Não & $7(23,3)$ \\
Você lava as mãos após usar produtos de limpeza? & \\
Sim & \\
Não & \\
Não uso produto de limpeza & \\
\hline \hline
\end{tabular}

Foi perguntado aos manipuladores em quais momentos eles acreditavam ser necessário lavar as mãos. As respostas estão apresentadas na figura 1, onde as mais frequentes foram: após usar o banheiro; sempre/toda hora; e quando for trocar de função. A maioria dos manipuladores (93,3\%) afirma lavar as mãos mais de cinco vezes durante a jornada de trabalho, e todos afirmam lavar as mãos quando chegam ao serviço e após usar o banheiro. Dados semelhantes foram encontrados por OLIVEIRA \& GONÇALVES (2015), onde 100\% dos manipuladores estudados afirmavam lavar as mãos frequentemente. 


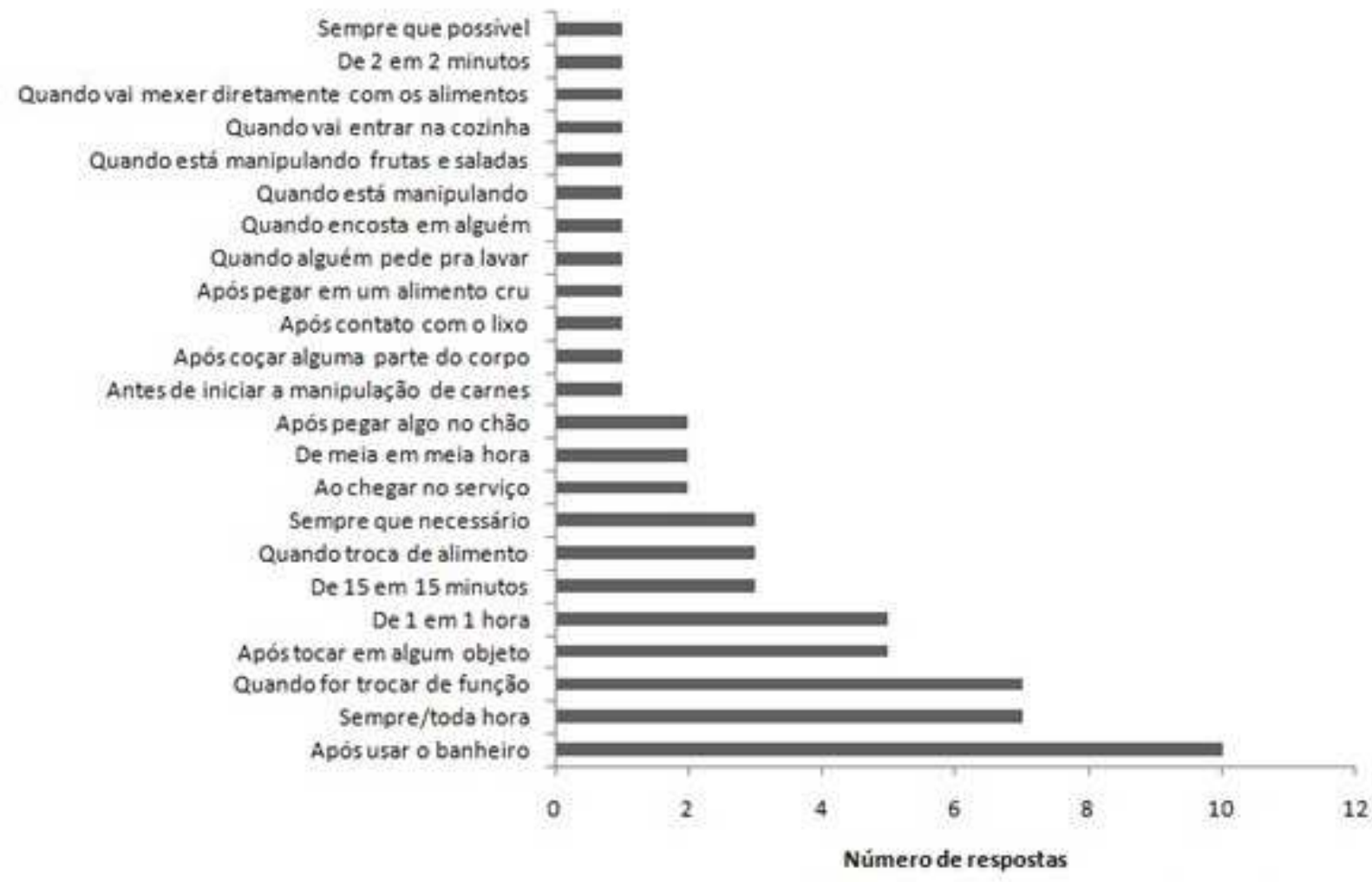

FIGURA 1. Momentos em que os manipuladores de uma Unidade de Alimentação e Nutrição de Uberlândia-MG julgam ser necessário lavar as mãos.

Por meio de um checklist, foram observados os itens: controle de saúde; presença de lesões e enfermidades; uso e adequação dos uniformes; higiene das mãos; comportamento; uso de toucas; uso de barba e adornos pessoais e aparência das unhas dos manipuladores de alimentos, e a presença de visitantes e se esses seguiam as mesmas normas atribuídas aos manipuladores. Os itens foram separados por grupos, e demonstrados na Figura 2. Pode-se verificar que a maioria dos itens teve grande porcentagem de adequação (85 a 95\%), exceto o item "comportamento dos manipuladores" que teve apenas $14 \%$ de atendimento às normas vigentes. O item "higienização das mãos" não foi demonstrado no gráfico, visto que, durante o momento destinado à observação, não foi possível identificar o momento da lavagem de mãos após tocar em objetos ou alimentos contaminados, após utilizar as instalações sanitárias e antes e após a manipulação de alimentos. No estudo realizado por MAYARA et al. (2014), que usaram checklist baseado na mesma resolução que o presente estudo, o item de manipuladores de alimentos apresentou, no geral, $80 \%$ de adequação. Já no estudo realizado por SANTOS et al. (2015), as análises mostraram apenas $28,5 \%$ de adequação. 


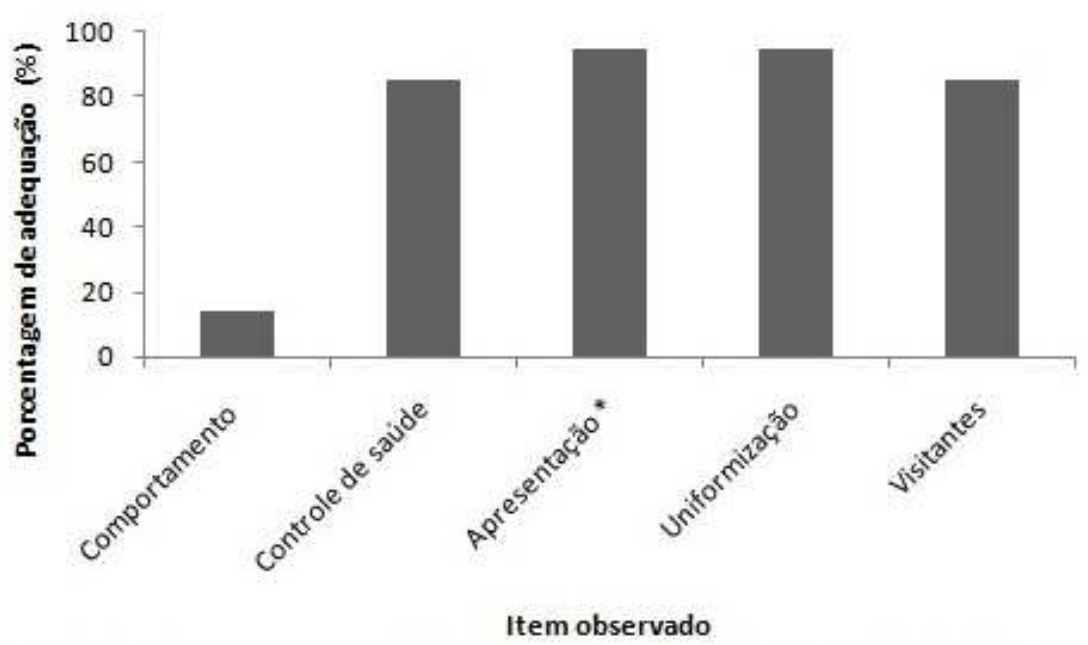

FIGURA 2. Adequação às boas práticas quanto à manipulação de alimentos e controle de higiene e saúde dos manipuladores em uma Unidade de Alimentação e Nutrição de Uberlândia-MG. *Apresentação: estado das unhas, uso de barba e adornos pessoais.

Na tabela 3 é apresentado o resultado da análise microbiológica de Staphylococcus aureus, micro-organismos mesófilos aeróbios, coliformes totais e termotolerantes (presença/ausência) nas mãos dos manipuladores.

TABELA 3. Análise microbiológica das mãos dos manipuladores de uma Unidade de Alimentação e Nutrição, na cidade de Uberlândia-MG.

\begin{tabular}{|c|c|c|c|c|}
\hline Manipulador & $\begin{array}{c}\text { Stephylococcus } \\
\text { aureus }\end{array}$ & $\begin{array}{l}\text { Mesófilos } \\
\text { aeróbios } \\
\text { (UFC/mão) }\end{array}$ & $\begin{array}{c}\text { Coliformes } \\
\text { totais }\end{array}$ & $\begin{array}{c}\text { Coliformes } \\
\text { termotolerantes }\end{array}$ \\
\hline$\overline{1}$ & Ausencia & $1,3 \times 10^{4}$ & Ausencia & Auséncia \\
\hline 2 & Ausência & $7,5 \times 10^{2}$ & Ausência & Ausência \\
\hline 3 & Ausência & $7,7 \times 10^{2}$ & Ausência & Ausência \\
\hline 4 & Ausência & $1,3 \times 10^{2}$ & Ausência & Ausência \\
\hline 5 & Ausência & $2,2 \times 10^{\circ}$ & Ausência & Ausência \\
\hline 6 & Ausência & $6,8 \times 10^{2}$ & Ausência & Ausência \\
\hline 7 & Ausência & $8,2 \times 10^{4}$ & Ausência & Ausência \\
\hline 8 & Ausência & $5,1 \times 10^{2}$ & Ausência & Ausência \\
\hline 9 & Ausência & $1.5 \times 10^{2}$ & Ausência & Ausência \\
\hline 10 & Ausência & - & Ausência & Ausência \\
\hline 11 & Ausência & $1,3 \times 10^{2}$ & Ausência & Ausência \\
\hline 12 & Ausência & $5,1 \times 10^{3}$ & Ausência & Ausência \\
\hline 13 & Ausência & $9.7 \times 10^{4}$ & Ausência & Ausência \\
\hline 14 & Ausência & $2,7 \times 10^{4}$ & Ausência & Ausência \\
\hline 15 & Ausência & - & Ausência & Ausência \\
\hline 16 & Ausência & $1,6 \times 10^{2}$ & Ausência & Ausência \\
\hline 17 & Ausência & $9,3 \times 10^{4}$ & Ausência & Ausência \\
\hline 18 & Ausência & $1,8 \times 10^{\circ}$ & Presença & Ausência \\
\hline 19 & Ausência & $4,3 \times 10^{2}$ & Ausência & Ausência \\
\hline 20 & Ausência & $3,3 \times 10^{2}$ & Ausência & Ausência \\
\hline 21 & Ausência & $3,7 \times 10^{4}$ & Ausência & Ausência \\
\hline 22 & Ausência & $1,2 \times 10^{=}$ & Ausência & Ausência \\
\hline 23 & Ausência & $4,5 \times 10^{3}$ & Ausência & Ausência \\
\hline 24 & Ausência & $1,8 \times 10^{2}$ & Ausência & Ausência \\
\hline 25 & Ausência & $4,7 \times 10^{2}$ & Ausência & Ausência \\
\hline 26 & Ausência & $5,1 \times 10^{4}$ & Ausência & Ausência \\
\hline 27 & Ausência & $2,2 \times 10^{4}$ & Ausência & Ausência \\
\hline 28 & Ausência & $3,9 \times 10^{4}$ & Ausência & Ausência \\
\hline 29 & Ausência & $4,5 \times 10^{3}$ & Ausência & Ausência \\
\hline 30 & Ausência & $3,2 \times 10^{2}$ & Ausência & Ausência \\
\hline Média & - & $1,9 \times 10^{2}$ & - & - \\
\hline
\end{tabular}


Staphylococcus aureus é um dos componentes da microbiota transitória das mãos e está dentre os micro-organismos mais frequentemente encontrados em surtos de doenças transmitidas por alimentos (BRASIL, 2015). Esta bactéria também pode ser encontrada na narina anterior e é facilmente transmitida aos alimentos por manipuladores colonizados (SILVEIRA et al., 2013). Os manipuladores podem transmitir esse agente aos alimentos quando tocam em alimentos já coccionados ou em alimentos desinfetados, ao tossir e espirrar, e ao utilizar panos para o contato com os alimentos (SILVA, 2005). No presente estudo não foi encontrada essa espécie em nenhuma amostra, demonstrando que os manipuladores em algum momento realizavam uma eficiente higiene das mãos. Foram encontrados apenas Estafilococos coagulase negativos, sendo duas amostras $S$. schleiferi e uma amostra S. warneri.

SILVEIRA et al. (2013), realizando análise de Staphylococcus aureus nas mãos de funcionários de uma Unidade Produtora de Refeições (UPRs), encontraram contaminação em $44,44 \%$ das amostras no momento do trabalho, e após a lavagem de mãos em apenas $16,66 \%$, mostrando que com a higienização das mãos é possível eliminar esse micro-organismo. Os manipuladores que continuaram contaminados mesmo após a lavagem de mãos, certamente cometeram falhas durante o processo de higienização ou se contaminaram logo após em consequência do contato com alguma superfície ou objeto. No estudo de OLIVEIRA \& GONÇALVES (2015), foi encontrada a presença desse micro-organismo em $14,29 \%$ dos manipuladores analisados, mesmo quando esses relatavam que realizavam a higienização das mãos corretamente.

No presente estudo, foi observado que todos os manipuladores lavaram as mãos com sabonete antisséptico inodoro, seguido de antissepsia com álcool líquido $70 \%$ antes da coleta microbiológica das mãos. Desta forma, todos se empenharam em realizar o procedimento correto. Mas, por outro lado, houve o viés de estarem sendo observados e saberem que iriam participar do estudo. Acredita-se que esses fatores tenham contribuído para a ausência de Staphylococcus aureus em todas as amostras.

Os Estafilococos coagulase negativos fazem parte da microbiota residente das mãos e, embora sejam bem resistentes à remoção mecânica ou agentes químicos e não eliminados mesmo com uma higienização adequada, não oferecem riscos aos indivíduos saudáveis. Porém, podem causar infecções em pessoas imunologicamente comprometidas (SANTOS, 2002; SHAMOTO et al., 2015).

Observou-se a presença de mesófilos aeróbios em $93,3 \%$ dos manipuladores analisados. As contagens variaram de $4,5 \times 10^{3}$ a $7,7 \times 10^{5} \mathrm{UFC} / \mathrm{mão}$, com média de $1,9 \times 10^{5} \mathrm{UFC} /$ mão. A contagem de micro-organismos mesófilos aeróbios é amplamente utilizada para analisar a qualidade higiênico-sanitária do alimento, sendo útil para verificar a eficiência dos procedimentos de higienização, o efeito da temperatura de conservação dos alimentos, e a vida útil do mesmo (CARDOSO et al., 1989). Quanto maior a contaminação por micro-organismos mesófilos aeróbios em um alimento, maior a possibilidade de encontrar micro-organismos patogênicos. Além disso, sua presença em números elevados pode indicar falhas de higienização, contaminação ambiental e deterioração do alimento (COELHO et al., 2010).

Embora não exista padrão microbiológico no Brasil para análise de microorganismos mesófilos aeróbios em mãos de manipuladores de alimentos, é de extrema importância esta análise microbiológica, visto que, por meio das mãos dos manipuladores, os alimentos podem ser contaminados. 
No estudo realizado por COELHO et al. (2010), foi encontrada contaminação por este grupo de micro-organismos com valores na ordem de $10^{6} \mathrm{UFC/mão.}$ Números mais expressivos foram encontrados por ALMEIDA et al. (1995), que encontraram valores médios de $10^{7} \mathrm{UFC} /$ mão.

Juntamente com a contagem de micro-organismos mesófilos aeróbios, a detecção de coliformes é muito utilizada, pois sua presença indica contaminação através de dejetos fecais ou higienização inadequada (CARDOSO et al., 1989). Os coliformes totais estão presentes nas fezes dos homens e animais, em vegetais, no solo ou águas residuais. Já os coliformes termotolerantes, são encontrados nas fezes dos homens e animais de sangue quente, e sua presença indica poluição fecal (SILVA, 2005).

No presente estudo, foi encontrada a presença de coliformes totais em apenas uma amostra de um manipulador, sem uma relação estatística que justifique este resultado. Números expressivos foram encontrados por LUZ \& FORTUNA (2015), onde $29,8 \%$ dos manipuladores estudados tinham presença de coliformes totais nas mãos.

Não foi encontrada a presença de coliformes termotolerantes em nenhuma amostra avaliada. Esse resultado, de acordo com as recomendações de SILVA JR. (2005) é considerado satisfatório e está coerente com as respostas obtidas nas questões feitas aos manipuladores, onde $100 \%$ deles afirmaram higienizar as mãos após o uso do banheiro. LUZ \& FORTUNA (2015) avaliando as condições higiênicosanitárias de manipuladores de merenda escolar também encontraram resultados semelhantes. Por outro lado, SOUZA et al. (2015), ao analisarem manipuladores de alimentos de comércio ambulante, verificaram a presença de coliformes termotolerantes em $20 \%$ das amostras.

\section{CONCLUSÃO}

Visto que não foi encontrada contaminação importante por micro-organismos patogênicos nas amostras analisadas, conclui-se que os manipuladores analisados realizaram a higienização das mãos adequadamente na ocasião da coleta. No entanto, foram observados alguns comportamentos que podem propiciar a contaminação dos alimentos durante a preparação, o que reforça a importância do treinamento, qualificação e monitoramento frequente para a garantia da manutenção das boas práticas de manipulação.

\section{REFERÊNCIAS}

ABREU, E. S.; MEDEIROS F. S.; SANTOS, D. A. Análise microbiológica de mãos de manipuladores de alimentos do município de Santo André. Revista Univap, v.17, n. 30, $2011 . \quad$ Disponível em: < http://revista.univap.br/index.php/revistaunivap/article/view/24>. doi: http://dx.doi.org/10.18066/revunivap.v17i30.24

ALMEIDA, R. C. C.; KUAYE, A. Y.; SERRANO, A. M.; ALMEIDA, P. F. Avaliação e controle da qualidade microbiológica de mãos de manipuladores de alimentos. Revista Saúde Pública, v. 29, n. 4, p. 290-294, 1995. Disponível em: < http://www.scielo.br/scielo.php?pid=S0034-

$89101995000400006 \&$ script=sci_abstract\&tIng=pt>.

doi: http://dx.doi.org/10.1590/S0034-89101995000400006. 
BRASIL. Agência Nacional de Vigilância Sanitária (ANVISA). Resolução RDC no 216, 15 de setembro de 2004. Dispõe sobre regulamento técnico de boas práticas para serviços de alimentação. Diário Oficial da União, Brasília, DF, 16 Set 2004.

BRASIL. Ministério da Saúde. Secretaria de vigilância em saúde - SVS. Unidade de Doenças de Veiculação Hídrica e Alimentar - UHA. Coordenação Geral de Doenças Transmissíveis - CGDT. Vigilância Epidemiológica das Doenças de Transmissão Hídrica e Alimentar - VEDTHA. Brasília: Ministério da Saúde; 2015. Disponível em: http://portalsaude.saude.gov.br/images/pdf/2015/novembro/09/Apresenta----o-dadosgerais-DTA-2015.pdf. Acesso em: 01 set. 2016.

CARDOSO, W. M; SILVA G. G.; CANO V. Análise microbiológica de alimentos. 2ed; Laboratório Merck; 1989. p. 22-24.

CARDOSO, R. C. V.; SOUZA, E. V. A.; SANTOS, P. Q. Unidades de alimentação e nutrição nos campi da Universidade Federal da Bahia: um estudo sobre a perspectiva do alimento seguro. Revista de Nutrição, v. 18, n. 5, p. 669-680, Set/Out, $2005.2 \quad$ Disponível em: < http://www.scielo.br/scielo.php?script=sci_arttext\&pid=S1415-52732005000500010>. doi: http://dx.doi.org/10.1590/S1415-52732005000500010

CENTERS FOR DIASEASE CONTROL AND PREVENTION - CDC. Diagnosis and Management of Food borne Illnesses: A Primer for Physicians and Other Health Care Professionals. MMWR 2004, april; 53 (No. RR-4): 1. Disponível em: http://www.uphs.upenn.edu/bugdrug/antibiotic_manual/CDCfoodbornerr04Apr04.pdf. Acesso em: 01 set. 2016.

CENTERS FOR DIASEASE CONTROL AND PREVENTION - CDC. Pathogens Transmitted by Food Contaminated by Infected Persons Who Handle Food, and Modes of Transmission of Such Pathogens. 2014. Disponível em: http://www.cdc.gov/foodsafety/pdfs/pathogens-by-food-handlers-508c.pdf. Acesso em: 01 set. 2016.

COELHO, A. I. M; MILAGRES, R. C. R. M.; MARTINS, J. F. L.; AZEREDO, R. M. C.; SANTANA, A. M. C. Contaminação microbiológica de ambientes e de superfícies em restaurantes comerciais. Ciência \& Saúde Coletiva, v. 15, Supl. 1, p. 1597-1606, 2010. Disponível em: < http://www.scielo.br/scielo.php?pid=S1413$81232010000700071 \&$ script $=$ sci abstract\&tlng $=$ pt $>$. http://dx.doi.org/10.1590/S1413-81232010000700071.

CONCEIÇÃO, M. S; NASCIMENTO, K. O. Prevenção da transmissão de patógenos por manipuladores de alimentos. Revista Verde (Pombal - PB - Brasil), v 9, n. 5 , p. 91-97, Dez 2014. Disponível em: < http://www.gvaa.com.br/revista/index.php/RVADS/article/view/3309>. 
KONEMAN, E. W.; ALLEN, S. D.; JANDA, W. M.; SCHRECKENBERGER, P. C.; WINN Jr., W. C. Diagnóstico microbiológico - Texto e atlas colorido. 5 ed. Rio de Janeiro: Medsi; 2001. 1465 p.

LARSON, E. L.; STROM, M. S.; EVANS, C. A. Analysis of three variables in sampling solutions used to assay bacteria of hands: Type of solution, use of antiseptic neutralizers, and solution temperature. Journal of Clinical Microbiology, v. 12, n. 3, p. 355-360, Sept, 1980. Disponível em: < https://www.ncbi.nlm.nih.gov/pmc/articles/PMC273590/>.

LUZ, T. C. S.; FORTUNA, J. L. Condições higiênico-sanitárias de manipuladores de merenda escolar de instituições de ensino de Teixeira de Freitas-BA. REB, v. 8, n. 2, p. 162-176, 2015. Disponível em: http://revistas.pucsp.br/index.php/reb/article/view/15463>.

MAYARA, N.; SILVA, M. G; BEZERRA, M. J.; BEZERRA, M. Q.; SANTOS, F. M.; SOUZA, E. A.; ARAÚJO, G.; SOUZA, G. V.; PORTO, C. K.; ARAÚJO, L. C.; FERNANDES, M. A.; LAPENDA, J. C. Condições higiênico-sanitárias das unidades produtoras de alimentos em hotéis do município de Caruaru, Pernambuco. Veredas

Favip, $\quad$ v. $7, \quad$ n. 2, 2014. Disponível em: < http://veredas.favip.edu.br/ojs/index.php/veredas1/article/view/232>.

MESSIAS, G. M.; REIS, M. E. R.; SOARES, L. P.; FERNANDES, N. M.; DUARTE, E. $\mathrm{S}$. Avaliação das condições higiênico-sanitárias de restaurantes do tipo self service e do conhecimento dos manipuladores de alimentos quanto à segurança do alimento na cidade do Rio de Janeiro, RJ. Revista Eletrônica Novo Enfoque, v. 17, n. 17, p. 73-88, 2013. Disponível em: < http://www.castelobranco.br/sistema/novoenfoque/files/17/12-giselle-bolsistaerik.pdf>.

OLIVEIRA, N. S.; GONÇALVES, T. B. Avaliação microbiológica das mãos de manipuladores de alimentos em creches da cidade de Juazeiro do Norte, CE. Revista Interfaces: Saúde, Humanas e Tecnologia, v. 3, n. 1, 2015. Disponível

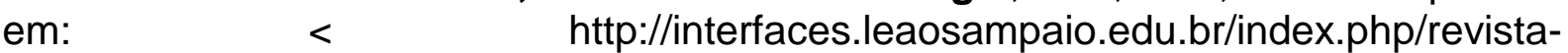
interfaces/article/view/252>. doi: http://dx.doi.org/10.16891/2317.434X.143

SCHARFF, R. L. Economic Burden from Health Losses Dueto Food borne Illness in the United States. Journal of Food Protection. v. 75, n. 1. p 123-131, 2012. Disponível em: < https://www.ncbi.nlm.nih.gov/pubmed/22221364>. doi: 10.4315/0362-028X.JFP-11-058.

SANTOS, A. A. M. Higienização das mãos no controle das infecções em serviços de saúde. RAS, v. 4, n. 15, Abr-Jun, 2002. Disponível em: < http://www.anvisa.gov.br/servicosaude/controle/higienizacao_mao.pdf>.

SANTOS, R. M. S.; GOUVEIA, D. S.; ROCHA, A. P. T.; SILVA, W. M.; LINS, A. D. F. Avaliação de restaurante universitário por meio do regulamento técnico de boas práticas para serviços de alimentação. Revista Verde (Pombal - PB - Brasil), v. 10, 
n.2, p. 26-32, Abr-Jun, $2015 . \quad$ Disponível em: http://www.gvaa.com.br/revista/index.php/RVADS/article/view/3417/2967>.

SILVA Jr, E. A. Manual de controle higiênico-sanitário em serviços de alimentação. 6 ed. São Paulo: Varela; 2005.

SILVEIRA, J.; CLEMENTE, I. H.; VIEIRA, C. R. W.; RAMOS, R. J. Avaliação microbiológica das mãos de manipuladores de alimentos de uma Unidade Produtora de Refeição (UPR) da grande Florianópolis. Revista Eletrônica Estácio Saúde, v. 2, $\quad$ n. 2, 2013. 2 Disponível em: < http://revistaadmmade.estacio.br/index.php/saudesantacatarina/article/view/672>.

SHAMOTO, I.; ISHIHARA, Y.; SATO, A.; USAMI, H.; MATSUDA, N.; OHTA, M. Dissemination of Staphylococcus warneri in the Hair of ICU Doctors. Advances in Microbiology, v. 5, n. 8, p. 599-603, August 2015. Disponível em: <http://www.scirp.org/journal/PaperInformation.aspx?paperlD=58654>. doi: 10.4236/aim.2015.58062

SOUZA, G. C.; SANTOS, C. T. B.; ANDRADE, A. A.; ALVES, L. Comida de rua: avaliação das condições higiênico-sanitárias de manipuladores de alimentos. Ciência \& Saúde Coletiva, v. 20, n. 8, p.2329-2338, 2015. Disponível em: < http://www.scielo.br/scielo.php?pid=S1413-

$81232015000802329 \&$ script $=$ sci_abstract\&tlng=pt>.

doi:

http://dx.doi.org/10.1590/1413-81232015208.14922014.

TAKAHASHI, C. C.; AMARAL, P. E.; SANTOS, L. C. L.; CONTIM, J. D.; PINTO, U. M.; NEVES, C. V. B.; FIGUEIREDO, S. M. Avaliação do treinamento de manipuladores de alimentos de restaurantes comerciais pelo ensaio ATPbioluminescência. Revista do Instituto Adolfo Lutz, v. 72, n 4, p. 318-23, 2013. Disponível em: < http://revistas.bvs-vet.org.br/rialutz/article/view/22896>. 